\title{
Germinando redes
}

\section{La propagación de las semillas}

DOI: $10.46932 / \mathrm{sfjdv2n5-059}$

Received in: Oct 1st, 2021

Accepted in: Dec 30th, 2021

\author{
Laura Vanesa Martínez Gordillo \\ Higher academic background: Diseñadora Industrial - Industrial Designer \\ Current Institution: Universidad Jorge Tadeo Lozano \\ Full address: Colombia, Bogotá - Calle 12 B bis A \#1-52 \\ Email: laurav.martinezg@utadeo.edu.co
}

\section{RESUMEN}

La propagación de las semillas es un documento estructurado como exégesis en el que se reflexiona sobre el trabajo realizado en torno a un proyecto de índole social y ecológica ubicado en el Barrio La Concordia en Bogotá, Colombia. Mediante la intervención y realización de una muestra cultural estética en las fachadas en conjunto con grafitis y agricultura urbana vertical se incita a los residentes del sector a recuperar su conexión con la naturaleza y ejercer desde su privacidad de forma pública y visible prácticas sostenibles. Germinando Redes hace uso de materiales reutilizables como las botellas plásticas y materiales naturales como el fique para su realización, consta de varias macetas colgantes distribuidas en las fachadas de manera particular para cada caso, busca así dinamizar los muros y paredes de este sitio histórico para que cada vecino pueda poner y quitar a gusto los muros verdes. Así mismo medita en las actividades sociales y económicas que hacen parte del barrio y la identidad barrial y encuentra que se pueden desarrollar y regenerar relaciones cooperativas entre los residentes produciendo cambios culturales alrededor de la comida orgánica creando nuevas dinámicas comunitarias que influyan en la identidad y apropiación del barrio.

Palabra clave: Agricultura urbana, arte urbano, Centro Histórico de Bogotá, identidad barrial, diseño sostenible.

\begin{abstract}
The propagation of seeds is a document structured as exegesis in which it reflects on the work done around a project of a social and ecological nature located in the Barrio La Concordia in Bogotá, Colombia. Through the intervention and realization of an aesthetic cultural sample on the facades in conjunction with graffiti and vertical urban agriculture, residents of the sector are encouraged to recover their connection with nature and employ sustainable practices from their privacy in a public and visible way. Germinating Networks used reusable materials such as plastic bottles and natural materials such as fique for its realization. Includes several hanging pots; distributed on the facades in a particular way for each case, thus seeking to energize the walls and walls of this historic site so that each neighbor can put and remove the green walls at ease. It also meditates on the social and economic activities that are part of the neighborhood and the neighborhood identity and finds that cooperative relationships can be developed and regenerated among the residents producing cultural changes around organic food creating new community dynamics that influence the identity and appropriation of the neighborhood.
\end{abstract}

Keywords: Urban agriculture, Urban Art, Bogotá Historical Downtown, Neighborhood identity, Sustainable design. 


\section{RELEVANCIA DEL PROYECTO PARA LA PRACTICA DEL DISEÑO}

A lo largo de este documento podrán apreciar que mi proyecto se centra en brindar soluciones participativas y perdurables que, en pequeña escala y replicadas beneficien o mejoren la calidad del ambiental local en torno a prácticas sostenibles y además generen nuevas dinámicas sociales.

Mi proyecto busca desempeñar el diseño desde el concepto del antojar y tentar a una comunidad impermeable a prácticas como la agricultura vertical; empezando desde la individualidad y ganándose la aceptación y voluntad de los residentes para la ejecución y multiplicación de Germinando Redes, con el fin de que sea un proyecto que se desempeñe por largo tiempo y tenga en cuenta las necesidades de los residentes, y actué desde la cooperación compromiso, toma de decisiones, y aporte de ideas.

Como verán a lo largo de este documento, como profesional uso el diseño como estrategia para obtener resultados derivados de la interacción comunal no siendo solo importante mi objeto si no lo que este pueda provocar y generar en aquellos que se permitan ser tocados por mi diseño.

\section{ABONANDO Y PREPARANDO LA TIERRA (INTRODUCTION)}

Germinando Redes empezó por mi disposición personal hacia la naturaleza, me gusta sembrar plantas y ver como día a día van cambiando y creciendo para convertirse en alimentos; cómo florecen y se trasforman, también es mi deseo que las personas puedan recuperar su conexión con la naturaleza, ejercer pequeños cambios que nos ayuden a llevar una vida en equilibrio con el mundo, crear relaciones de reciprocidad con los seres vivos, respetar a la naturaleza y vincularnos con ella, llevando vidas más sostenibles, más orgánicas y aprendiendo un arte tan valioso como es la siembra.

Además de la naturaleza también quería vincular mi hogar y mi barrio, lugar en el que he vivido desde siempre y que he visto transformarse a lo largo de los años.

Bogotá. (2019, 4 de mayo) capital de la República de Colombia, está constituida por 20 localidades, es eje central político, económico, administrativo, industrial, cultural, artístico, deportivo y turístico del país. En una de sus localidades, se encuentra un barrio llamado La Concordia situado en el centro tradicional de Bogotá, siendo específicos en la localidad 17 La Candelaria, corazón histórico y cultural de la ciudad, ubicado a 2650 msnm a las faldas del cerro de Guadalupe goza del tan inesperado clima de Bogotá siendo posibles mañanas soleadas y tardes lluviosas, vientos fuertes y noches de luna llena realmente fríos, he comprobado por experiencia propia que en algunas ocasiones mientras en los barrios aledaños al cerro llueve en otros lugares de la ciudad se presentan días soleados.

La localidad de La Candelaria es símbolo del origen y la historia de la conquista y creación de Bogotá como ciudad, pero además de eso, es un sector donde conviven en equilibrio tradición y modernidad. Fue hacia los años 1970 que se creó la Corporación de La Candelaria con el propósito de 
rescatar el patrimonio histórico de diferentes barrios entre ellos La Concordia, reconocida por poseer La Plazoleta del Chorro de Quevedo, menos conocida por su nombre como barrio y si por este importante lugar histórico en donde se dice estableció su guarnición militar Gonzalo Jiménez de Quesada, (secretaria distrital de planeación, 2009). También es un lugar controversial ya que se alega que en un principio fue ahí donde se fundó la ciudad y otros dicen que la fundación oficial se dio en La Plaza Mayor hoy conocida como La Plaza de Bolívar.

Fue hacia los años 1970 que se creó la Corporación de La Candelaria con el propósito de rescatar el patrimonio histórico de diferentes barrios entre ellos La Concordia, reconocida por poseer La Plazoleta del Chorro de Quevedo, menos conocida por su nombre como barrio y si por este importante lugar histórico en donde se dice estableció su guarnición militar Gonzalo Jiménez de Quesada, (secretaria distrital de planeación, 2009). También es un lugar controversial ya que se alega que en un principio fue ahí donde se fundó la ciudad y otros dicen que la fundación oficial se dio en La Plaza Mayor hoy conocida como La Plaza de Bolívar.

Esto ha generado dinámicas divertidas, puesto que La Concordia al conservar arquitecturas y calles empedradas de la época es usualmente referida como el lugar de Fundación por muchos guías turísticos ya que estos elementos visuales enriquecen sus relatos incluyendo una placa de piedra ubicada en una de las casas que circundan la plazoleta y que da fe de la fundación de Bogotá en este sector. La plazoleta del Chorro (véase figura 1) es circundada por construcciones coloniales y de principios del siglo XX, siendo apetecida por tal razón por turistas y visitantes. Hoy en día estas casas coloniales e históricas han sido adaptadas a café-bares, restaurantes y tiendas de artesanías, orientadas a economías locales como la gastronomía y el entretenimiento.

Figura 1: Plazoleta del Chorro de Quevedo

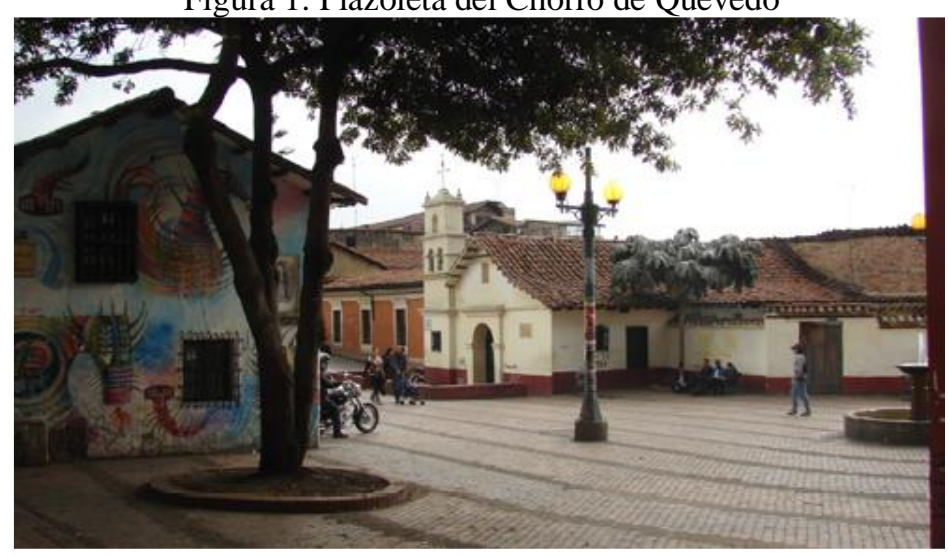

Por este motivo, los residentes han transformado lo que en un principio era y es un barrio residencial a un barrio más comercial y eje turístico de la ciudad, llevando a sus diversos actores a tener dinámicas individuales supliendo sus intereses personales y apagando el sentido de pertenencia y 
comunidad del barrio, esto resultó en poca apreciación y poco respeto por el otro y lo otro, como aquello que no me afecta directamente. Fueron estas reflexiones las que me llevaron a realizar un proyecto que involucrara mi pasión por la naturaleza y mi deseo de cambiar las dinámicas que se llevan actualmente en mi barrio.

Por lo tanto, Germinando Redes se dio a la tarea de buscar aquello que era fundamental y eje de interés tanto de residentes como de comerciantes para desarrollar un proyecto de diseño industrial que logrará involucrarlos y captará su interés a largo plazo. En consecuencia, el meollo del asunto se centra en el antojar, el desear; así es que, dando ejemplo se busca que los residentes tomen cartas en el asunto y emulen determinadas prácticas desde su privacidad.

Para esto determiné que un factor en común de gran importancia tanto para residentes como para comerciantes son las fachadas de sus viviendas, puesto que representan un gran atractivo para turistas, transeúntes y también clientes a la hora de visitar el barrio.

Así pues Germinando Redes hace uso de las fachadas de viviendas y negocios y las une hacia una práctica natural sostenible, comprendida por medio de la adaptación de la agricultura urbana vertical, convirtiéndose en un agente de transformación local dotando de poder y responsabilidad a sus participantes para cambiar no solo la perspectiva del barrio y fortalecer las relaciones humanas sino además generar un impacto local ambiental, reverdecer este pedacito de ciudad y combatir el deterioro ambiental.

Germinando Redes antoja a los vecinos a pintar sus paredes de naturaleza comestible en armonía con lo urbano y las muestras artísticas hechas en fachadas, para incentivar el turismo y curiosidad de visitantes y además generar orgullo, apropiación y solidaridad entre sus residentes en la búsqueda de cuidarnos unos a otros y de dinamizar las economías locales en torno a fachadas vivas comestibles.

En la ejecución del proyecto yo me comporto como diseñadora y usuaria de mi propio producto, ya que todo se basa en el antojar a los residentes por medio del ejemplo, viéndome a mí misma como residente quiero facilitar el uso de mi objeto y así mismo lograr ver las fallas y mejoras sobre el uso, ya que como residente conozco las necesidades, ventajas y desventajas del contexto para ofrecer las soluciones puntuales para que los residentes una vez ejecuten el proyecto no lo abandonen a la mitad por obstáculos que puedan surgir en su implementación.

Germinando Redes está compuesto principalmente de tres grandes componentes, 1. Las fachadas del barrio, 2. Plantas comestibles sembradas verticalmente y 3. La expresión visual de realidades mediante grafitis.

Al realizar una observación concienzuda del barrio me di cuenta de que, aunque muchos vecinos se negaron a mi idea de una huerta comunitaria, si hay un interés por sembrar; varios restaurantes y cafés 
cuentan con plantas comestibles como aromáticas y condimentarías. E incluso varios residentes tienen plantas como café y aromáticas visibles al transeúnte. Esto me motivo muchos más al pensar que si hay un interés en el tener una conexión con la naturaleza y usar alimentos sembrados por sí mismos.

\section{RAICES QUE SE ENTRETEJEN (ASSOCIATIONS)}

Mediado por el comercio y el turismo el movimiento humano se ha enfocado en la prestación de servicios que suplan económicamente las necesidades de cada individuo, siendo que cada quien desde su privacidad ha desarrollado la forma de vivir de las dinámicas del barrio, ya sea creando un café-bar, un restaurante, un hostal, agencias de turismo, entre otros, no se ha creado una comunidad fuerte que involucre a todos y busque promover la identidad del barrio en una dirección, lo que lleva a cada quien a hacer uso de su creatividad para lograr poner un negocio que sea perdurable y fructífero en la zona en la que este ubicado.

Entre otros lugares están la Plaza de la Concordia o la misma plazoleta del Chorro de Quevedo, espacios públicos que son en su mayoría aprovechados en beneficio de terceros y no de habitantes del barrio. Muestras culturales como los cuenteros o el teatro a la calle son agradables e interesantes para todos, transeúntes, turistas, visitantes e incluso para nosotros los residentes pero que más satisfactoria sería que los propios jóvenes y niños del barrio pudieran estar involucrados en actividades como estas.

El barrio La Concordia se ha convertido en una especie de espacio público que no es de nadie, pero es usado por todos, es así como se presentan situaciones como: no me importa arrojar basura o dañar el mobiliario porque no es mi barrio y yo no vivo aquí, o del otro lado no me importa que le estén dañando la fachada a mi vecino o que su andén este lleno de basura ya que no es mi negocio y no me afecta a mí. Como residente y persona que estima su barrio y que con mente positiva cree que las cosas pueden mejorar dado que no se puede llegar a un nivel mayor de egoísmo e impertinencia, mi objetivo es dejar de ser un actor pasivo de este escenario y sembrar la semilla que produzca el cambio.

Desde mi individuo, como diseñadora y amante de la naturaleza empecé una rigurosa observación, en búsqueda de la oportunidad que me permitiera involucrar a todos los habitantes del barrio en la transformación, construcción y fortalecimiento de las relaciones humanas y además de ello el cuidado y aprendizaje de la tierra, la naturaleza, mediante la ejecución de acciones positivas dependiendo más de nosotros mismos y menos de factores externos, y reforzar así mismo nuestra salud y bienestar a través de los alimentos orgánicos cultivados por nosotros mismos. Me di entonces a la tarea de estudiar aquellos factores estéticos por los que los residentes se veían más preocupados, encontrando que muchos hacen uso de las plantas sean grandes o pequeñas para atraer visitantes, cambiándolas a lo largo del año y según ocasiones especiales. 
Es por ello que para generar una cultura significativamente nueva como diría (Escobar, 2016, p.p 157 -182) me enfoque en conceptos mencionados como es el cambiar las prácticas que se llevan desarrollando en el barrio y enfocarlas hacia la diversidad, la auto-organización social y ecológica y el fortalecimiento de producir localmente; desde hace ya unos 10 años La Concordia se ha reconocido por producir localmente la famosa Chicha $^{1} \mathrm{y}$ dentro de las muy diversas formas de producirla es un barrio al que muchos acuden por esta bebida y otras experiencias que se desarrollan en torno a la misma, como beberla en un totumo, o la clásica botella envuelta en bolsa de papel, extravagancias como la Chicha de colores, entre otras. (1 Bebida fermentada a base de mazamorra de maíz y otros cereales originarios de América, cuyos almidones y cereales son fermentados y transformados en alcohol por acción de las levaduras, elaborada artesanalmente. )

Estas dinámicas considero dotan al barrio de características que lo llevarían a triunfar en el desarrollo local de más productos en torno a prácticas sostenibles con gran probabilidad de éxito. Otro factor estético que es y está tomando fuerza en el barrio son los grandes murales artísticos y/o grafitis presentes en abundantes lugares incluyendo la plaza de mercado y el parque de La Concordia. Han sido de gran interés para los residentes al observar que era menor el daño a sus edificaciones cuando estas presentaban estas muestras artísticas y para los comerciantes al notar la afluencia de turistas dando lugar a recorridos turísticos enfocados en estudiar estos grafitis y a sus creadores, que por supuesto incrementaban las ventas.

Me adentré en términos como la agricultura urbana y la permacultura (Permacultura. 2019, 14 de abril) respuesta positiva a crisis ambientales y sociales, siguiendo sus principios básicos: uno de ellos, el cuidado de la tierra ya que si no la cuidamos y no está sana el ser humano entre muchos otros seres vivos no podrán subsistir. El cuidado a las personas, procurando que todos tengan las mismas oportunidades, con el acceso a los recursos necesarios para vivir dignamente y por último la repartición justa poniendo límites al consumismo y tomando solo lo necesario.

De igual forma varios de sus 12 principios, como lo son: el observar e interactuar diseñando soluciones particulares para cada caso. Valorar los recursos naturales haciendo el mejor uso posible de la abundancia y minimizando la dependencia de recursos no renovables, y tal vez el más significativo, integrar más que segregar a partir de la cooperación, repartiendo las funciones, mejorando y fortaleciendo las relaciones.

Todo esto con la motivación y la creencia de que pequeñas acciones viniendo de ciudadanos pensantes y comprometidos pueden cambiar el mundo (Transition Network, 2009)

La trama de la vida de Fritjof Capra que habla de La Ecología Profunda y como esta entiende la vida como una interdependencia fundamental entre todos los fenómenos y como todos estamos inmersos 
y somos dependientes de los procesos de la naturaleza, me introdujo a varios conceptos que me parece importante destacar:

- No hay separación del humano u otra cosa del entorno natural

- Reconocimiento del valor intrínseco de todos los seres vivos, siendo el humano una hebra de la trama de la vida

- Experimentar un sentido de pertenencia y de conexión con el cosmos como un todo.

Entonces, comprendo que no es el ser humano superior o mejor que otras especies, de hecho, es todo lo contrario no somos más que una parte de un gran sistema, un sistema que tiene diferentes participantes que cumplen diferentes funciones y tanto o más que el ser humano hacer posible todo lo que ocurre día a día

Otros referentes como Terraformar de Harold Martínez al igual que Natalie Jeremijenko y su conferencia El arte del cambio mental ecológico me hacen creer y darme cuenta que tanto como yo en todo el mundo hay personas que desean abrirle un campo a la naturaleza en los entornos urbanos, la ejecución de pequeñas acciones que poco a poco cambian al mundo y a las comunidades y como diría Jaime Lerner en su libro Acupuntura Urbana hacer reaccionar a las comunidades con un pinchazo para ayudar a curar, a sanar, propagando una acción; en mi caso por medio del ejemplo, del antojo, de la motivación para unir a una comunidad y poder aportar no solo económicamente si no socialmente, generando nuevos vínculos, nuevas interacciones y dinámicas que partan del respeto y afecto hacia la naturaleza.

Estas fueron las bases que dieron estructura a Germinando Redes, ayudándome a disponer de ciertos requerimientos para su realización que comentaré más adelante en el capítulo de crecimiento y desarrollo.

\section{IDENTIFICANDO EL TERRENO (CONTEXT)}

En 1538 (secretaria distrital de planeación, 2009) el conquistador Gonzalo Jiménez de Quesada llegó al que era conocido como el reino de los chibchas por la región de Veléz, avanzó hacia los territorios del Zipa, quien gobernaba en Bacatá tomándola y estableciendo su ejército en el palacio del monarca, situado en la zona que el conquistador llamó el Valle de los Alcázares.

Quesada hace la construcción de la ciudad siguiendo sus parámetros propios; efectuó la fundación en Teusaquillo lugar de descanso del zipa, en la plazoleta que hoy se conoce como El Chorro de Quevedo, estableciendo doce chozas de paja una modesta iglesia, históricamente aceptada la fundación se dio el 6 de agosto de 1538 . 
Durante la década de los 70 La Candelaria adquirió sus características actuales, localizándose muchos grupos de teatros en viejas casas, escogido como logar de residencia de muchos artistas, se formaron así organizaciones culturales estableciéndole cierta imagen de bohemia cultural. Está ubicada en el centro de Bogotá, limita al sur con la localidad de San Cristóbal, al oriente con la localidad de Santa Fe y al norte y occidente con las localidades de Los Mártires y Antonio Nariño.

Geográficamente el territorio de la Candelaria es de topografía inclinada, por su ubicación al borde de los cerros orientales, presenta una temperatura media anual de $14^{\circ}$, posee 21 barrios (secretaria distrital de planeación, 2009) uno de ellos La Concordia (véase figura 2) que significa acuerdo o armonía entre personas.

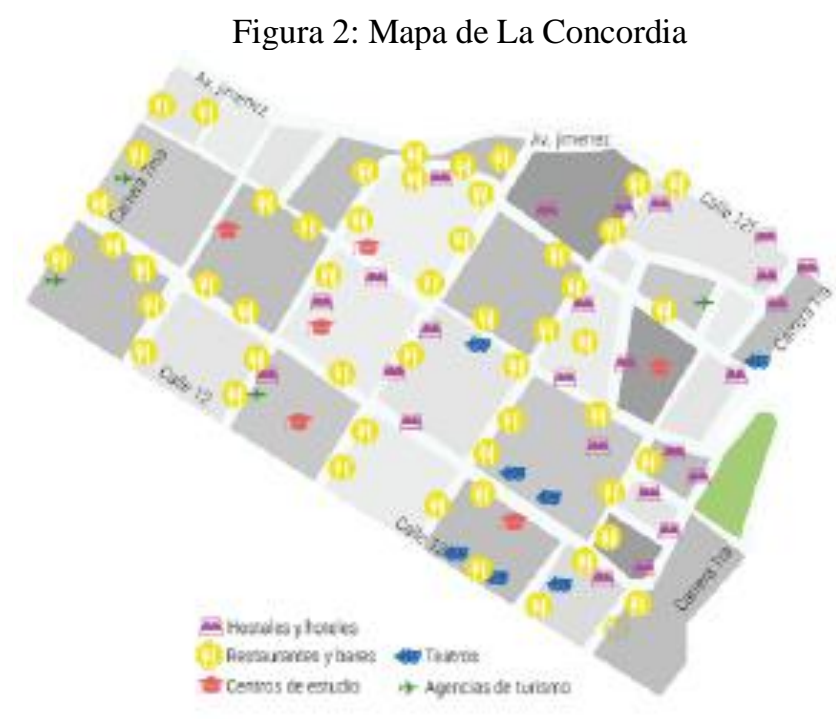

Podríamos decir que en armonía conviven el comercio y la vivienda, el turista y el residente, un barrio tan diverso que podemos encontrar desde teatros, hostales, restaurantes, bares, cafés, museos, patrimonio arquitectónico, ferreterías, plaza de mercados, supermercados, tiendas artesanales, panaderías y cafeterías, papelerías, universidades, colegios y jardines infantiles. Podríamos comparar La Concordia con "un arroz atollado" al que le agregas diferentes carnes, alguna que otra verdura, condimentos y sale un platillo tan único y delicioso que puedes encontrarte dos arroces atollados hechos por diferentes personas con más o menos ingredientes y aun así disfrutar los dos por igual.

Buscando la armonía también entre la naturaleza y lo urbano, entre lo individual y lo público, entre la comunidad y el individuo está Germinando Redes un proyecto que al antojar busca la transformación de pensamiento y de actuar de los residentes. Al intervenir las fachadas de los residentes con naturaleza viva estudié los orígenes del uso de la vegetación en la arquitectura, encontrando que en un principio fue usada por sus ventajas de ofrecer aislamiento superior en respuesta a condiciones climáticas adversas. El 
uso de la vegetación en la arquitectura goza de la interesante capacidad de modificarla, siendo una de sus funciones estéticas por la que es y ha sido usada. (Navarro, 2013).

En el barrio La Concordia su función está más arraigada a lo estético y como he dicho anteriormente no solo es disfrutada por sus propietarios sino también por sus visitantes. Se sabe de construcciones coloniales que aún conservan fuentes de piedra rodeadas de generosos jardines como lo son La Casa de Poesía Silva, La Casa de La Moneda entre otras casas que han sido adecuadas como teatros y que aún conservan sus jardines, de igual forma edificios administrativos como La Alcaldía Mayor y El instituto Distrital de Patrimonio Cultural.

Dentro de los comercios y casas residenciales se destaca la recursividad, con la realización de jardines colgantes o en balcones, algunos usan inclusive ventanas y rejas para enverdecer sus viviendas; muchos restaurantes suelen poner a las puertas de sus negocios dos plantas enmarcando la entrada mientras se encuentra abierto el lugar.

La vinculación entre fachadas y agricultura está a pocos pasos de convertirse en realidad, usando como muestra y ejemplo mi casa, que cuenta ya como un atractivo para turistas y transeúntes por su jardín colgante recursivo sustentado por algunos vigas y palos de escoba y aunque pequeña y no de arquitectura colonial siempre ha sido punto de atención ganándose un recorrido por el mundo en diferentes cámaras que vienen de vacaciones y se hospedan justo al frente; nos esforzamos por mantener nuestra fachada limpia y nuestro jardín bien cuidado haciendo cambios continuos en las plantas, en este curioso jardín he tenido diversas plantas desde ornamentales como hortensias hasta aromáticas como caléndula, yerbabuena, toronjil y tomillo de las cuales aún conservo varias y uso frecuentemente en mi cocina (véase figura 3,4 y 5).

Haciendo más visible su encanto y atracción lograré contagiar a los residentes y comerciantes a cultivar plantas comestibles que servirán como interés turístico y alimenticio. Diseñar soluciones particulares que se adapten y puedan replicarse en otras fachadas, ofreciendo una muestra estética cultural fácil de adecuar y de realizar para que cada vez más y más residentes se vean tentados a hacerlo en sus hogares y comercios.

Como he mencionado Germinando Redes no solo busca llamar la atención de residentes y visitantes, Germinando Redes es el medio por el que se transformarán las dinámicas sociales del barrio, integrándonos en un camino sostenible, creando apropiación por nuestro espacio y compromiso y responsabilidad por lo comunal, llegando así en un futuro a poder desarrollar prácticas participativas entorno a otros temas, viéndonos no solo como individuos que obtienen ganancias si no como sociedad que piensa en el bienestar de todos. 
Figura 3, 4 y 5: Fachada de mi casa, plantas aromáticas

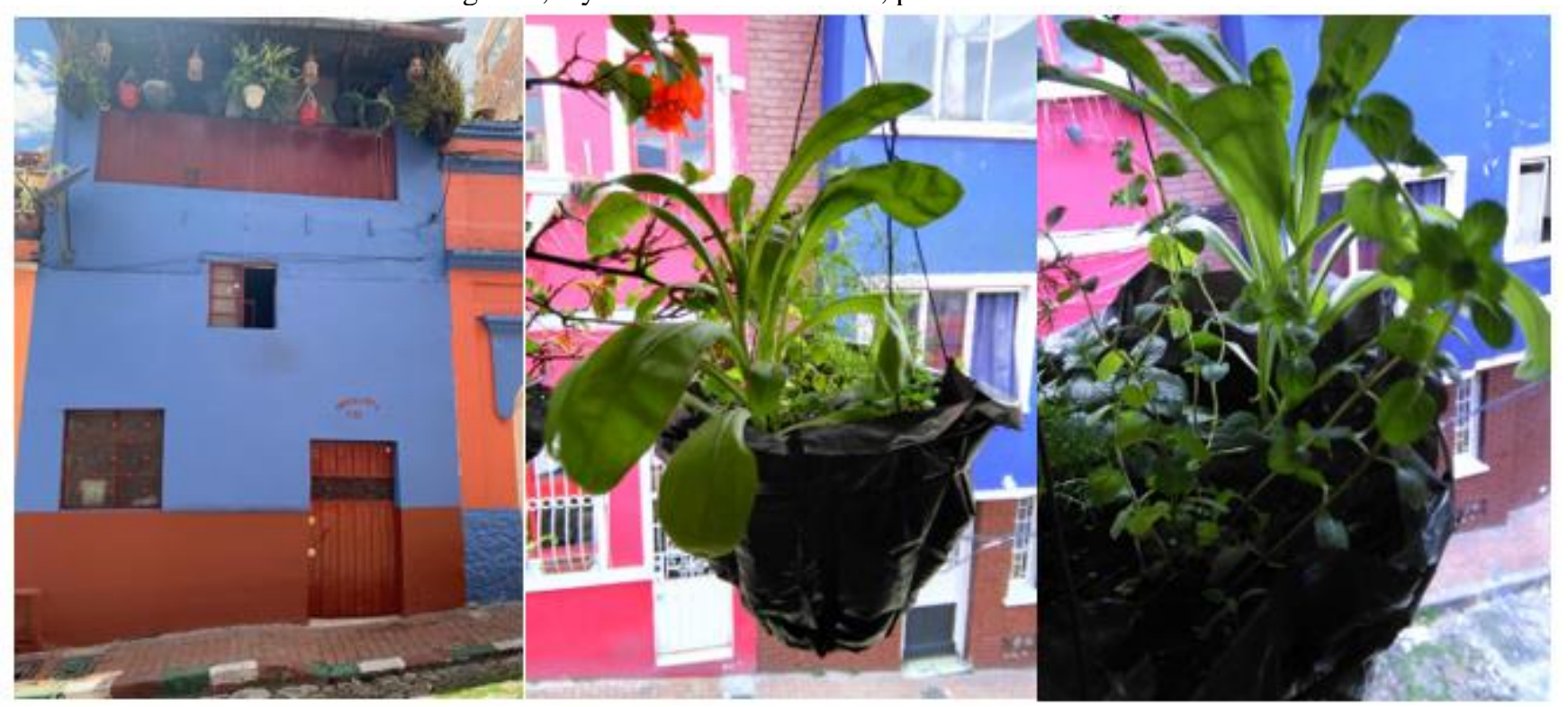

\section{CRECIMIENTO Y DESARROLLO (ELABORATION AND DEVELOPMENT)}

En un principio quería usar solo plástico para realizar las macetas, pero me costó manejarlo y adaptarlo como yo quería las primeras propuestas estaban lejos de ser tentadoras y llamativas. Dado que cada casa y negocio tiene sus características particulares uno de los requisitos es que sea adaptable y posible de diseñar de acuerdo con las exigencias y creatividad en sus fachadas.

El objetivo de Germinando Redes es generar un movimiento que antoje a los residentes del Barrio La Concordia a realizar muestras culturales y estéticas mediante fachadas vivas comestibles grafiteadas vinculadas a sus hogares y negocios generando distinción y comida orgánica en el sector. Mi hipótesis es que si yo como diseñadora muestro a los residentes las posibilidades que ofrecen las fachadas vivas comestibles como alternativa estética y funcional podre tentarlos a replicarlo en sus hogares.

Mis palabras clave son:

Antojar: ¿Que necesitan y desean los residentes?

Individual: ¿Como lo privado se vuelve público?

Transformación de pensamiento: Dando ejemplo, compartiendo opiniones y preocupándonos unos por otros

Crianza de lo natural: Producir, generar, nutrir y cuidar una nueva dinámica social

Comunidad: Grupo de personas que colaboran entre sí y generan interdependencia, unión y pertenencia. 
Mis requerimientos son desarrollar una práctica sostenible, haciendo uso de los recursos no aprovechados, despertar el interés de los residentes y visitantes, concebir a partir de la colaboración ya que lo que quiero es el empoderamiento del barrio por parte de los residentes.

A continuación, describiré las construcciones de mi última propuesta y podrán observar todas las consideraciones que tuve en cuenta y como se fue desarrollando la elaboración de la maceta y sus requerimientos al ser un cultivo de zona dura, lo cual significa que la plantación no se da en el suelo si no en recipientes que en este caso son colgantes:

Figura 6: Ingredientes para la siembra vertical (De izquierda a derecha, Turba, Cascarilla de arroz, tierra negra, semillas)
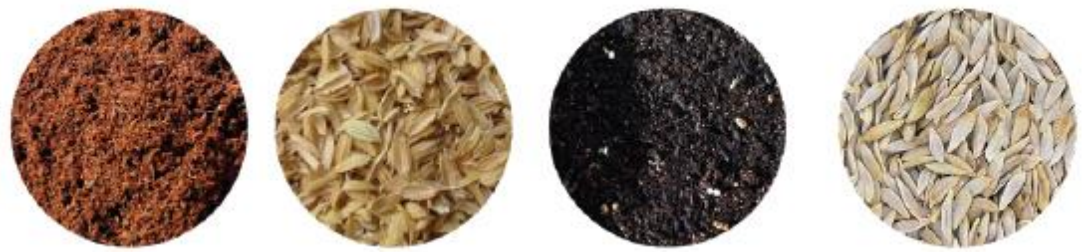

\section{CONSTRUCCION DE LA MACETA}

Para la maceta se hace un tejido con botellas de plástico y fique otorgándole resistencia, además en el interior se adapta una tela especial que retiene la tierra en el momento del riego. (véase Figura 7)

Figura 7: Construcción de la maceta, paso a paso.

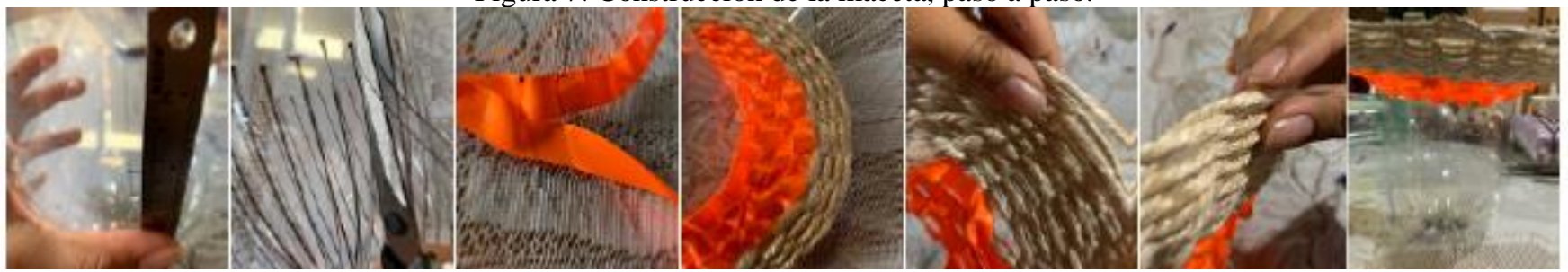

\section{APROXIMACION A LA COMUNIDAD}

Para empezar a dialogar con los vecinos y entender cuál era su apreciación del lugar y su opinión sobre las plantas realice unos dispositivos de aproximación, entrevistas gráficas sobre lo que consideraban importante en el barrio. (véase figura 8)
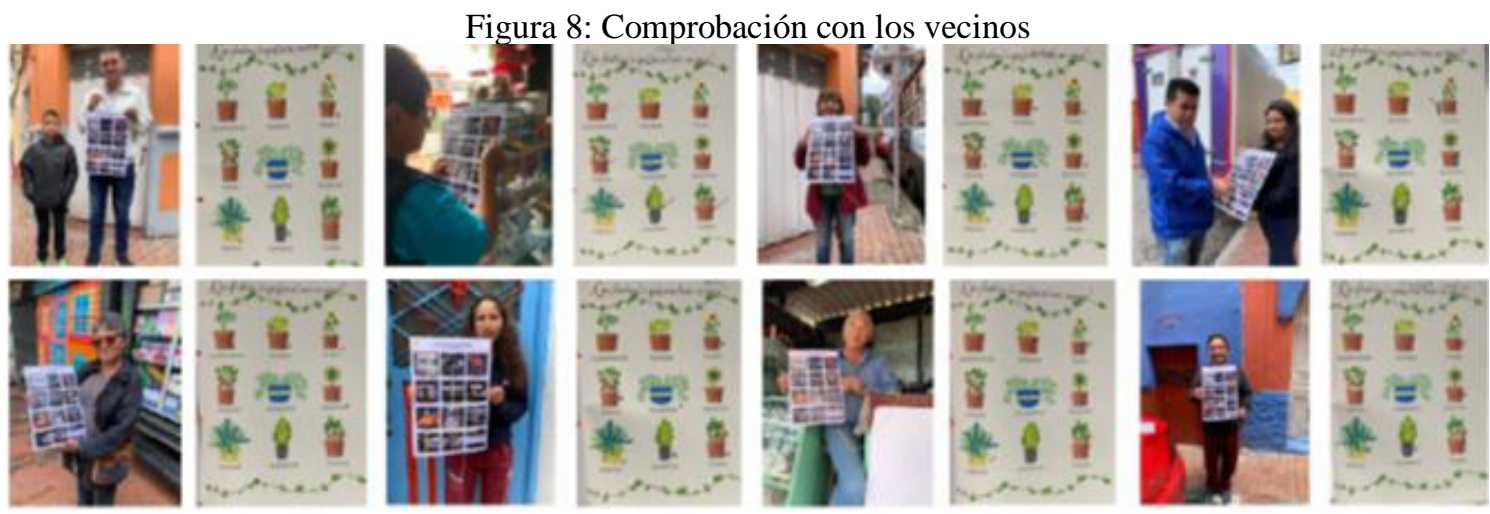


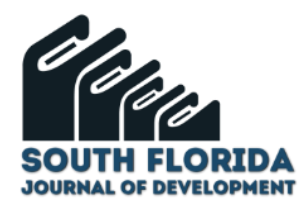

Con el fin de empezar a despertar el interés de los vecinos y empezar a visibilizar mi proyecto, realice un movimiento en el que realizaba la construcción de las macetas al frente de mi fachada, esto genero conversaciones y preguntas por parte de los residentes que en su mayoría se veían atraídos positivamente al elemento. A este lo denominé Puesta en escena (Véase figura 9)
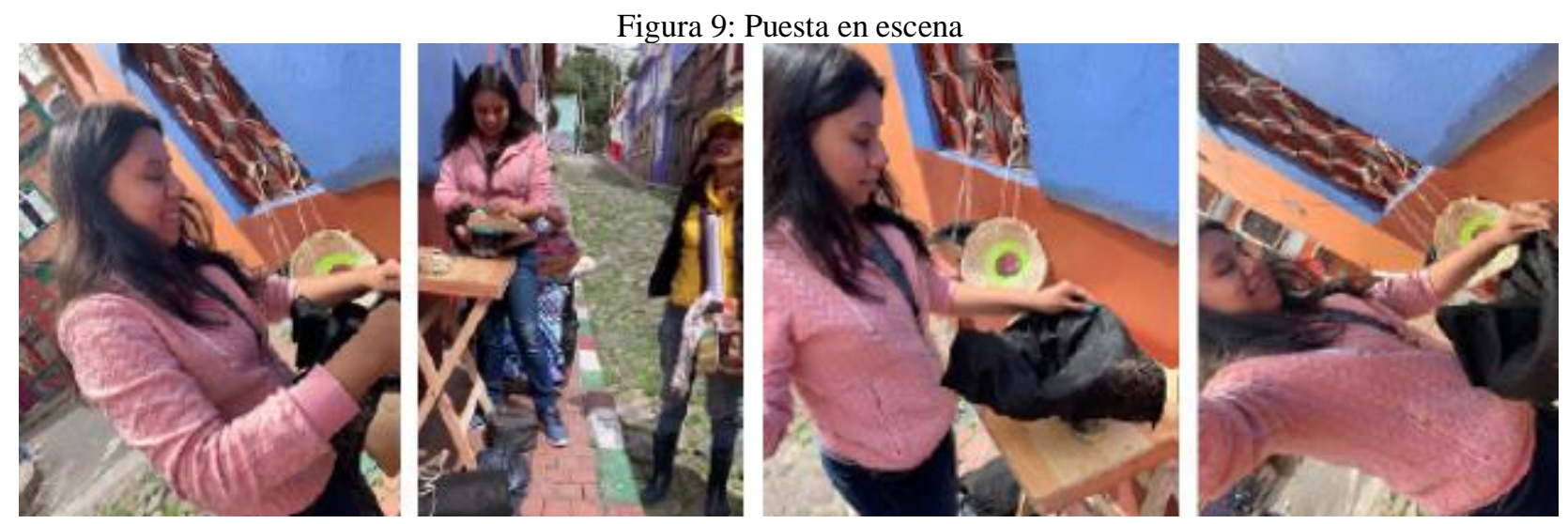

\section{PROTOTIPANDO LA FACHADA VIVA COMESTIBLE EN MI FACHADA}

Figura 10: Elaboración fachada viva comestible
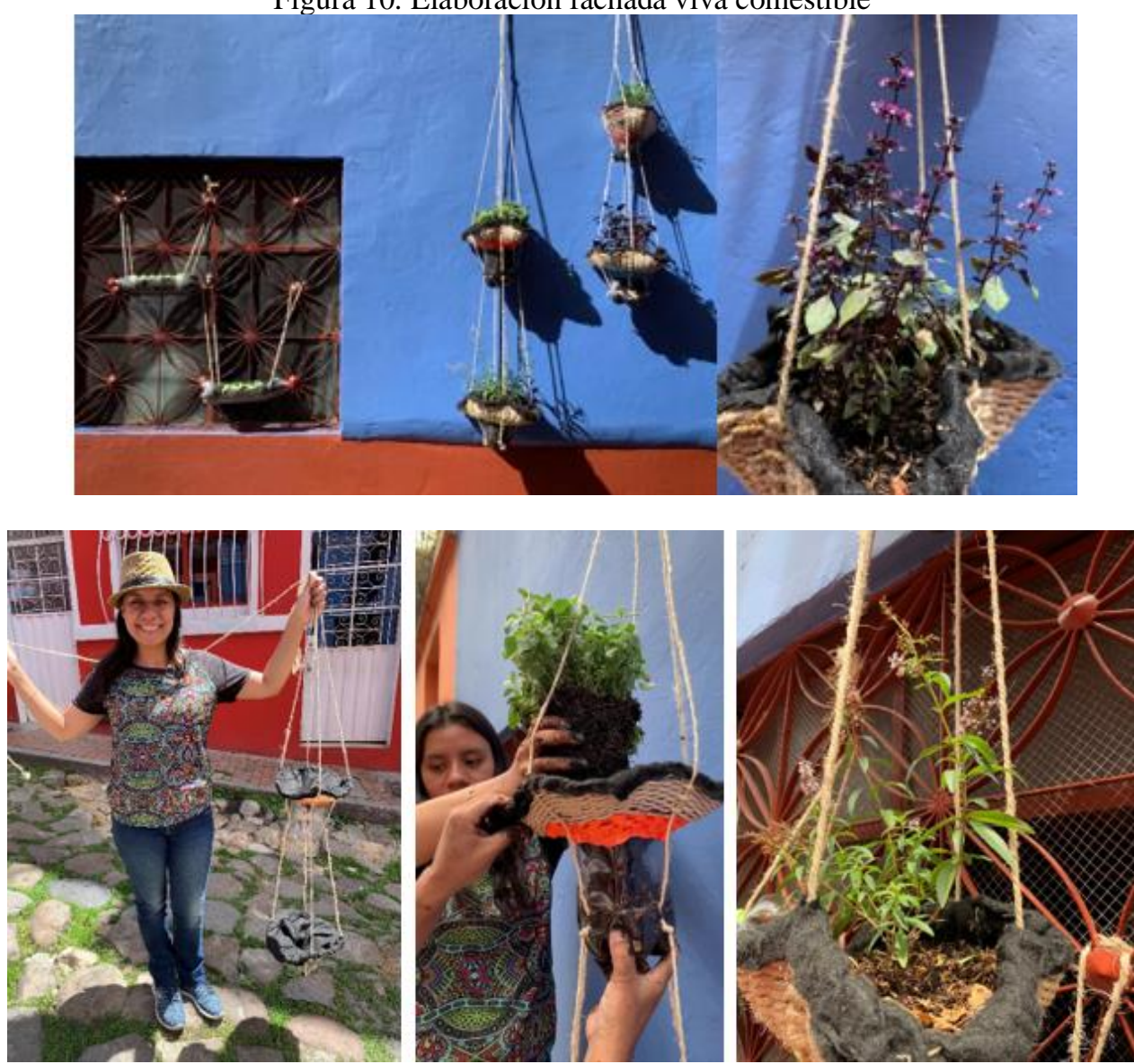


\section{PODANDO IDEAS Y COMBATIENDO PLAGAS (CONCLUSIONS)}

Germinando Redes es un proyecto que va más allá de una muestra estética, es solo el medio por el cual se busca recuperar una comunidad, generando unión y fortaleciéndonos como grupo en torno a una práctica que espera suscitar en los residentes iniciativa a más temas que involucran a la comunidad, temas de aprovechamiento de nuestro barrio y sus múltiples ramas culturales y deportivas que puede ofrecer.

Generar preocupación y responsabilidad hacia temas de seguridad y cuidado de nuestro barrio, compromiso con nuestros habitantes y las prácticas que desarrollamos en el barrio

Es un proyecto en desarrollo que se retroalimentara de mi comunidad y evolucionara de acuerdo con como ellos deseen aplicarlo en sus fachadas, es importante realizar las acciones que antojen a los residentes para lograr llegar a más y más vecinos, replicando poco a poco una acción y generando reacciones.

Dentro de los pasos a seguir, uno de ellos incluye a mi vecina Doña Paulina (ver figura 11) quien se mostró realmente interesada en la implementación de las fachadas y con quien me encuentro realizando las macetas para replicarlas en su hogar.

Además, he hablado con otra vecina Carmenza (Ver figura 12) quien me aconsejo realizar un portafolio para presentar mi proyecto en la Alcaldía Local con su ayuda al pertenecer a varios programas beneficiarios de la comunidad.
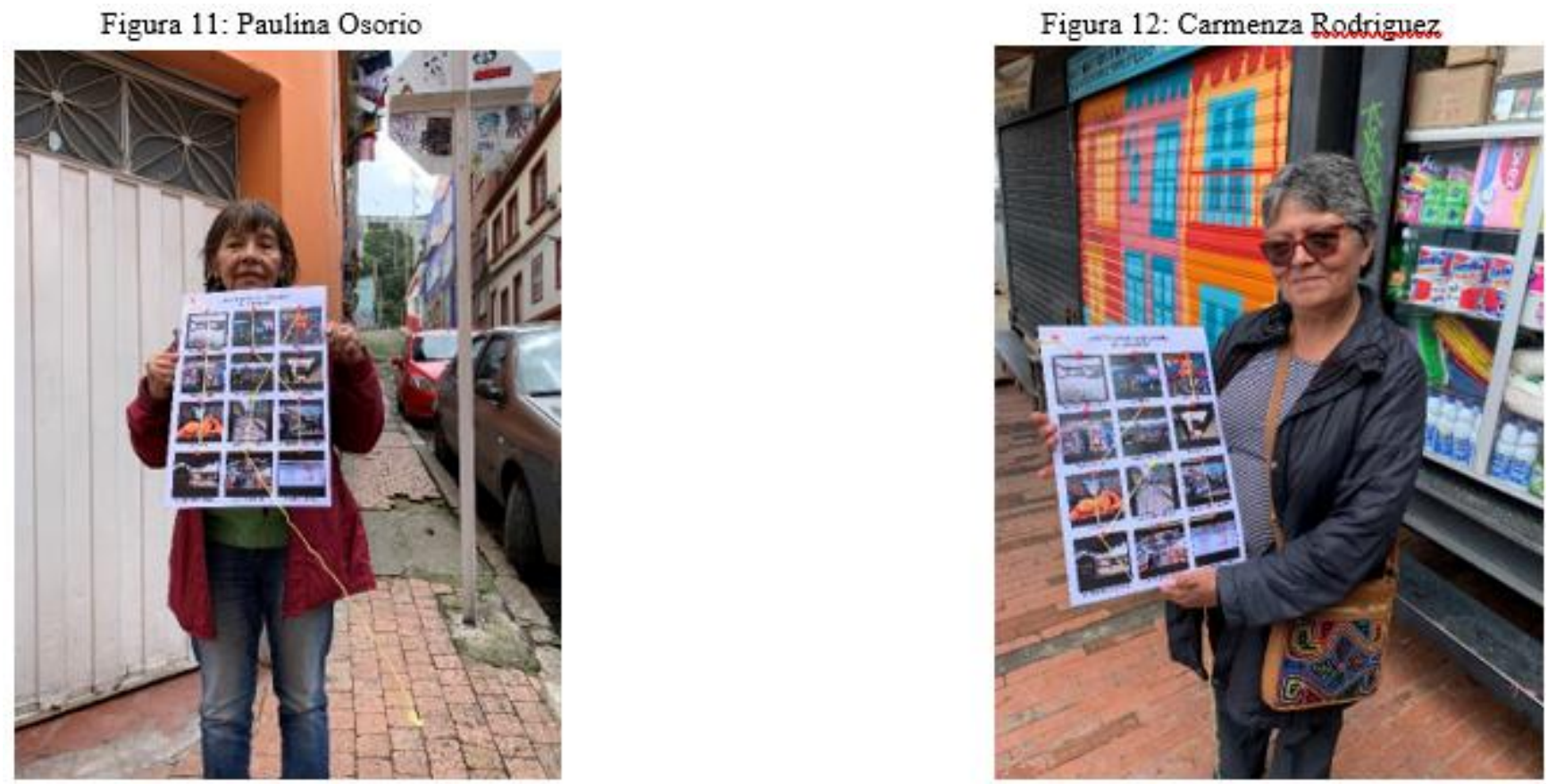

El paso a seguir se divide básicamente en dos ramas: una de ellas lo técnico-productivo en donde debo poner en práctica el último método que he decidido utilizar para los soportes en la pared y analizar 
cómo funciona en los aspectos funcionales para el riego y el crecimiento de la planta y por supuesto como soporte de las macetas y el aspecto estético en la mezcla con el grafiti.

Otro factor fundamental es el riego capilar por cordón, en un principio pensé en un sistema de riego por goteo, pero al realizar más exploraciones, y al darme cuenta que podía ser un sistema demasiado complejo que podría dañar estéticamente la muestra y al pensar en cómo se surtiría de agua dado las diversas fachadas, materiales de construcción y su acceso a las tuberías, elegí el método de riego capilar por cordón, el cuál deseo implementar en mi fachada para comprobar su funcionamiento y eficiencia.

Seguiré trabajando en los prototipos de las macetas que llevan sobre ellos la tarea de ser quizá el elemento provocativo más importante del sistema, ya que si estos son lo suficientemente tentadores, fáciles y económicos de realizar los residentes se verán más atraídos y querrán tenerlos en sus propias casas.

Todo lo anterior relacionado con la puesta en escena, mejorar todos los aspectos funcionales y estéticos para incrementar las reacciones de los vecinos a la fachada viva comestible e incitarlos a unirse, he pensado que ya replicada en la fachada de Doña Paulina será cada vez más fácil tentar a más vecinos.

Este proyecto me hace ver que el diseño tiene muchos más campos que abarcar a parte de la producción industrial, encuentro que es posible codiseñar no solo con profesionales, sino que dentro de una comunidad se puede encontrar esa colaboración y ese crecimiento profesional, mediante el aporte de ideas y conocimientos desde todos los puntos de vista. Germinando Redes me hace creer que el diseño puede ser el medio por el que se transforma el pensamiento y el ser de una comunidad.

Germinando Redes es más que un proyecto de grado, es un proyecto que deseo ver hecho realidad y que espero encuentre las personas adecuadas para que me ayuden a nutrirlo y hacerlo crecer para algún día cosechar sus frutos y promoverlo en muchas otras partes.

Actualmente y debido a la pandemia COVID-19, junto con mi familia tuvimos que recurrir a nuevos proyectos y emprendimientos, ya que perdimos nuestro trabajo; esta situación aunque negativa nos incito a buscar alternativas y nuevas oportunidades para progresar económicamente; siendo así que iniciamos un negocio en nuestra propia casa, haciendo uso de la fachada; empezamos a vender bebidas fermentadas entre las que se encuentra la Chicha, bebida de la que hable anteriormente, esto me ha permitido conocer diferentes personas que en busca de un buen producto se acercan a nuestra casa.

Lo interesante y positivo es que muchas personas se interesan en nuestra fachada debido a las plantas, antojándose y elevando su curiosidad por el diseño de las mismas, he conocido personas interesadas de diferentes partes de Bogotá que se sienten atraídas por mi proyecto, es así que, por medio de una actividad económica, la venta de un producto listo para el consumo, he iniciado conversaciones con diversas personas, llenándome de esperanza entorno a la producción comunal de mi proyecto. 

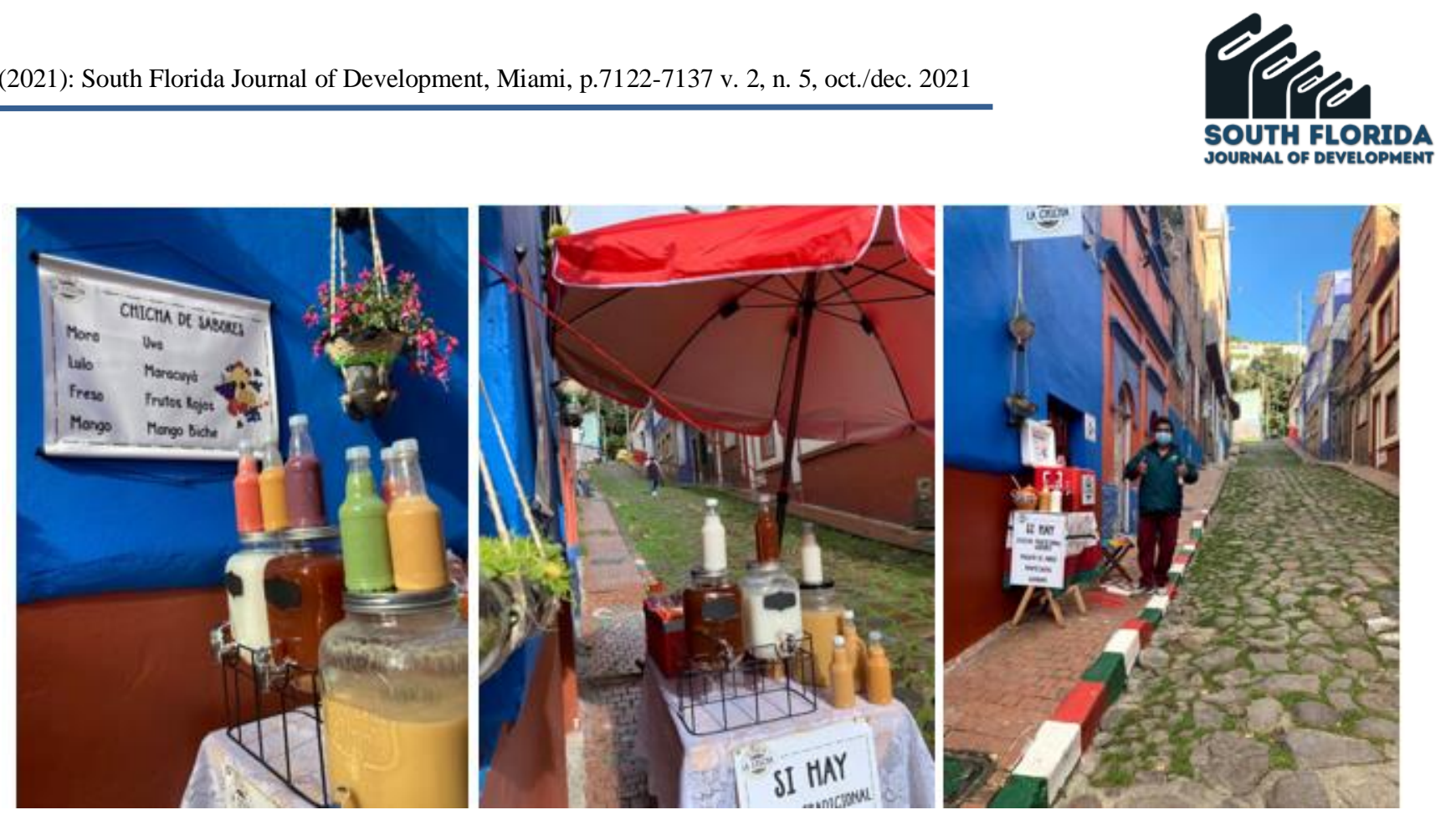


\section{REFERENCIAS}

1. Agricultura de guerrilla. (2017, 7 de septiembre). Wikipedia, La enciclopedia libre. Fecha de consulta: 19:51, mayo 5, 019 desde: https://tinyurl.com/y385vwzg

2. Bogotá. (2019, 4 de mayo). Wikipedia, La enciclopedia libre. Fecha de consulta: 01:50, mayo 6, 2019 desde https://tinyurl.com/y2kgxry7

3. Capra, F, (1998) El contexto cultural, Ecología profunda: un nuevo paradigma. En F. Capra. La trama de la vida una nueva perspectiva de los sistemas vivos. (pp 25-36). Barcelona: Anagrama.

4. Chicha, definición y etimología de los fermentados originarios de América (s.f). The Beer Times. Fecha de consulta: 19:27, abril 29, 2019 desde: https://tinyurl.com/yyq9byxy

5. Colciencias. (2019, 17 de noviembre). Wikipedia, La enciclopedia libre. Fecha de consulta: 17:58, noviembre 18, 2019 desde https://es. wikipedia.org/w/index.php?title=Colciencias\&oldid=121382017.

6. Enlucimiento de fachadas (s.f). Instituto Distrital de Patrimonio Cultural. Fecha de consulta: 12:06, abril 4, 2019 desde http://idpc.gov.co/enlucimiento-fachadas/

7. Escobar, A, (2016). Diseño para las transiciones. En A. Escobar (Ed). Autonomía y diseño: la realización de lo comunal. (pp. 157-182). Popayán: Editorial Universidad del Cauca.

8. Escobar, A, (2018) Habitabilidad y diseño: la interdependencia radical y la terraformatividad de las ciudades. En A. Escobar. Astragalo cultura de la arquitectura y la ciudad, numero 25 América, epistemologías del sur. ¿Metanoia o impenitencia arquitectónica?. (pp 20-22). Argentina: Universidad Abierta Interamericana.

9. Figura de portada: Barrio La Concordia Bogotá, centro, 29 de abril de 2019. En Facebook. Recuperado del día 18 de noviembre de 2017 de: https://tinyurl.com/y3gfnto3

10. Navarro, J, (2013). Los jardines verticales en la edificación. Valencia: Universitat Politècnica de València

11. Permacultura. (2019, 14 de abril). Wikipedia, La enciclopedia libre. Fecha de consulta: 02:34, mayo 7, 2019 desde https://tinyurl.com/y2djgg5a

12. Riego por goteo. (2019, 22 de abril). Wikipedia, La enciclopedia libre. Fecha de consulta: 14:24, abril 4, 2019 desde https://tinyurl.com/y2bfmugh

13. Secretaria Distrital de Planeación (2009). Conociendo la localidad de la candelaria. Bogotá.

14. Transition Network. (Productor). (2009). In transition 1.0. De https://vimeo.com/8029815

15. Universidad del Rosario (2019, 18 de noviembre). Experimentos sobre reconciliación política en Colombia. Fecha de consulta: noviembre 18, 2019 desde https://www.urosario.edu.co/jurisprudencia/jurisprudenciareconciliacion/ur/Postconflicto/

16. Vargas, S (2016) La variación de los cuerpos en las relaciones. En S. Vargas. Espacio urbano, naturaleza y relaciones sociales: por una sostenibilidad afectiva. (pp 54 - 55). São Paulo: Revista Psicología: Teoria e Prática. SP, jan -abr. 2016.

17. 100.000 Strong in the Americas. (2019). 100.000 Strong in the Americas. Fecha de consulta: $16: 46$, noviembre 16, 2019 desde http://www.100kstrongamericas.org/el-fondo-de-innovacion-100-000-strong-in-the-americasanuncia-las-instituciones-beneficiarias-de-subvenciones-fundacion-metlife-financia-nuevas-alianzas-deeducacion-superior-para-estudios-en-el-extra/ 